A closer look into the European Energy Performance Certificates under the lenses of behavioural insights - a comparative analysis

Peer-reviewed author version

TARANU, Victoria \& VERBEECK, Griet (2018) A closer look into the European Energy Performance Certificates under the lenses of behavioural insights - a comparative analysis. In: Energy efficiency (Print), 11 (7), p. 1745-1761.

DOI: $10.1007 / \mathrm{s} 12053-017-9576-6$

Handle: http://hdl.handle.net/1942/25379 


\title{
A closer look into the European Energy Performance Certificates under the lenses of behavioural insights - a comparative analysis
}

\author{
Victoria Taranu*1and Griet Verbeeck ${ }^{1}$ \\ 1: Faculty of Architecture and Arts \\ Hasselt University \\ Agoralaan Gebouw E, B-3590 Diepenbeek, Belgium \\ e-mail: victoria.taranu@uhasselt.be, griet.verbeeck@uhasselt.be
}

Published in the Energy Efficiency Journal

\begin{abstract}
The Energy Performance Certificate (EPC) aims promoting energy efficiency in the residential sector by allowing prospective buyers and renters to compare dwellings in terms of current and potential energy performance. Yet, the impact of the EPC on the purchase and renovation decisions is limited. The research hypothesis is that the framing of the information is an important determinant alongside the calculation method and the training of the certifiers. By framing of the information is meant the content, the wording and the layout. The present paper analyses how the technical information is translated for the dwellers and focuses on a possible heuristic interpretation of the information. Firstly, a theoretical framework of deliberative and heuristic thinking is presented, with its implication to policy making. Secondly, the findings of a qualitative inquiry of existing certificates, undertaken in two phases (a comparative analysis and a focus group) are presented. The certificates of nine European countries/regions revealed a wide range of information framings and potential nudges that have been analysed through the 'lenses' of behavioural insights. Even if nudging is not a purpose, the heuristic thinking might influence the understanding of the information since no message is neutral. Contrary to common misinterpretation that nudging exploits exclusively individual' $s$ heuristic thinking, certain type of nudges address the rationality of the people by avoiding an existing bias. These findings were analysed in depth in a focus group with experts. Recommendations are provided in order to render the EPC an effective communication tool with the dwellers.
\end{abstract}




\section{Introduction}

One of the key policy instruments for promoting energy efficiency in the building sector in Europe is the Energy Performance Certificate (EPC). The certificate was introduced first with the Directive 2002/91/EC (EC 2002) that stipulated that member states should ensure the certificate "is made available to the owner or to the prospective buyer or tenant when the building is constructed, sold or rested out". The implementation of the EPC was reinforced with the recast 2010/31/EU (EC 2010) that required the inclusion of the energy performance information at the moment of advertisement the property for sale or for rent. All EPCs contain an energy performance indicator and recommendations for the improvement of the energy efficiency. Both directives specify that besides the energy performance, the certificate has to include reference values such as minimum energy performance requirements "in order to make it possible for owners or tenants of the building or building unit to compare and assess its energy performance" (EC 2010). Therefore, the EPC is an information provision tool that aims to correct the market failure of asymmetric information. Besides, the recommendations might correct individual failures such as bounded rationality and bounded willpower (Bubb and Pildes 2014) and encourage the uptake of energy efficiency measures.

Up to now, various EU reports and projects have monitored the implementation of the certificate and its impact on the real estate market and on the uptake of energy efficiency measures (Mudgal et al. 2013; RenoValue). Literature shows mixed results or limited influence on the price of selling and renting (Christensen et al. 2014; Mudgal et al. 2013; Wahlstrom 2016; Harsman et al. 2016), as well as on energy renovation decisions (Christensen et al. 2014; Wade and Eyre 2015).

There might be various causes of the low influence of the certificate. Each member state had certain degree of freedom in deciding on the calculation method, the content and the layout. Most of the reports and projects focus on quality assurance of the calculation method and the professional training of the energy experts (Arcipowska et al. 2014; Maivel et al. 2016; Harsman et al. 2016). At an early stage of implementation, studies have analysed existing EPCs and hypothesised over its future implementation (BPIE 2010; Perez-Lombard et al. 2008). Their main focus was WHAT should be included rather than HOW.

Yet few of the EU projects and reports that follow the implementation of the certificate consider its quality of communication. One of the exceptions is the EU project IDEAL EPBD: Improving Dwellings by Enhancing Actions on Labelling for the EPBD (IDEAL EPBD Project Improving Dwellings by Enhancing Actions on Labelling for the EPBD). In the framework of the project, the impact of the EPC on the house owners was explored (Backhaus et al. 2011). 
The parameters were: how easy it is to understand the certificate, its perceived usefulness and trust. Surveys of the IDEAL EPBD project revealed the trade-off between intelligibility on one hand and usefulness and trust on the other hand. The certificates of the UK and the Netherlands are easy to understand and the recommendations are easy to remember, while at the same time, these are not perceived as useful. The certificates of Germany and Denmark show an opposite pattern. Besides, the German EPC contains more technical terms and concepts, that renders it more difficult to understand in comparison with the others. Yet, the certificates of Germany and Denmark with more detailed and tailored information are perceived as a reliable and trustful source of information (Backhaus et al. 2011). These findings regard previous versions of the EPCs compared to our study since the data of the surveys date back to 2008. Nevertheless, it underlines the importance of how to render the technical information more accessible, without losing its credibility and trust.

Another report that explores the content and the layout of the EPCs is the report on the implementation of the EPBD (Sutherland et al. 2015). Regarding the recommendations, there is the trade-off between the cost and content of the certificate. Personalized energy advice is more costly than a list of standardised recommendations. The report states that the layout and user-friendliness are crucial, recommending less technical terms and icons. It explores certain aspects of the content and layout of the certificates, yet it states the need for further research in order to adapt it to the needs of the users.

The research hypothesis of our research is that the framing of the information is an important explanatory factor for the effectiveness of the EPC, alongside calculation method and quality assurance. Information framing of the following two key messages of the EPC will be analysed under the optics of behavioural insights, taking into account the rational and heuristic thinking:

- Energy performance indicator

- Recommendations for measures to improve the energy performance (e.g. wall insulation)

In the present paper, by framing of the information is meant the following aspects: the content, the wording and the layout, since in the case of the energy performance indicator these are inseparable. The article summarizes and discusses the findings of a qualitative analysis in two phases: a comparative analysis and a focus group. The comparative analysis of the EPCs of nine different countries/regions had the aim to identify and compare the wide variety of possible information framings of the energy performance indicator and of the recommendations. The analysis takes into account that dwellers have both rational and heuristic thinking and might have biases in their interpretation of the 
information. The findings of the first phase were further discussed in a focus group with experts both in energy efficiency and in behavioural sciences. Besides gaining additional insights on the potential nudges and biases, the focus group aimed to gain insights on which information framings must be tested in an experimental way with dwellers. Finally, recommendations for improving the EPC as a communication tool are provided.

\section{Theoretical framework}

\subsection{Dwellers as both rational and heuristic decision makers}

Many policies promoting energy efficiency in the residential sector rely on the assumption that house owners are exclusively rational. Yet the actual decisions are affected by limited memory, limited attention and limited cognitive abilities (Simon 2000). When processing the information, people often avoid engaging in effortful, cognitive thinking - System 2, due to a shortcut - System 1 (Thaler and Sunstein 2009). The latter is heuristic, effortless and automatic and people are usually unaware of it. Even though System 1 is useful for taking small decisions in our everyday life in a fast manner, it might be inappropriate for important decisions such as purchase or renovation of a dwelling. The rational processing of the information of the EPC might be affected by unconscious errors, commonly named biases (Tversky and Kahneman 1974). Characteristics of the certificate, such as complexity of the information, choice overload, lack of salience are only some of the factors that might contribute to a heuristic thinking.

Besides, people do not always take cold-minded and rational decisions because they are affected by emotions - affect heuristic (Finucane et al. 2000). The influence of the emotions might be underestimated because people often rationalise the decision made based on emotions with rational arguments afterwards. "We don' $t$ see "A house" : We see a handsome house, an ugly house. '. We choose houses we find attractive and then justify these choices by various reasons." (Zajonc 1980). Therefore the information regarding the energy performance of the house might have a smaller impact on the purchase decision even if available. Certain aspects of the certificate, such as the image of the dwelling, might play a role in this regard.

If in general biases influence the correct estimation of probability, in economics application, biases are "errors when attempting to maximize the utility $U(x)$ " (Rabin 1998). For example, temporal discounting is characteristic to investments where the benefits occur in the future (Frederick et al. 2002). These savings of the recommended energy efficiency measures of the EPC might weight much less than the initial 
investment, even for positive net present values (BIT 2011).

Information framing does not equal, but it might include the framing effect bias. In certain cases, the decisions are affected by the wording of the message in positive or negative terms (Kahneman and Tversky 1979). An example is presenting the same statistics in "97\% of success rate" or " $3 \%$ chances of failure rate" that might influence the decision-making process.

\subsection{Existing policies that take into account behavioural insights}

The most well-known application of findings from behavioural economics to policy is nudging. According to R. Thaler and C. R. Sunstein, a nudge is "any aspect of the choice architecture that alters people's behaviour in a predictable way" (Thaler and Sunstein 2009). It belongs to the behavioural paternalism approach, the main principle of which is to incline toward the best solution, without forbidding the other choices. According to C.R. Sunstein, anything that does not involve a strong incentive while preserving the free choice qualifies as a nudge (Sunstein 2014). Other scientists, among whom R. Bubb and R. Pildes, claim that this definition is too broad. They reckon that a nudge should not affect the decision of a homo economicus (Bubb and Pildes 2014). Therefore, we propose the following definition: any change in the choice architecture that affects heuristic thinking or the balance between System 1 and System 2 thinking.

A common misinterpretation of the nudge is to consider that it only exploits the biases. Nudges can also enhance the cognitive processing of the information by avoiding complexity and certain biases. These are according to R. Baldwin (Baldwin 2014) — first degree nudges, see Table 1. Another definition of first degree nudge is the one aiming to 'debias' the decision-maker (Lunn 2013). C.R. Sunstein refers to this type of nudges as System 2 nudges, or 'educational nudges' (Sunstein 2016). Yet, information provision only qualifies as a 'first degree nudge', if aiming to avoid a certain bias, see Table 1. Exemplifying is the EAST method (Make it Easy, Attractive, Social and Timely) that advocates for rendering the message simple and salient (Hallsworth et al. 2014). 
Table 1 Three types of nudges. Adapted from R. Baldwin (Baldwin 2014)

\begin{tabular}{|l|l|l|l|}
\hline & $\begin{array}{l}\text { First degree } \\
\text { nudge }\end{array}$ & $\begin{array}{l}\text { Second degree } \\
\text { nudge }\end{array}$ & $\begin{array}{l}\text { Third degree } \\
\text { nudge }\end{array}$ \\
\hline Relation to bias & $\begin{array}{l}\text { Avoid an existing } \\
\text { bias }\end{array}$ & $\begin{array}{l}\text { Use an existing bias } \\
\text { towards a predictable } \\
\text { outcome }\end{array}$ & Induce a new bias \\
\hline $\begin{array}{l}\text { System1 (heuristic) } / \\
\text { System 2 (rational) }\end{array}$ & $\begin{array}{l}\text { From System 1 } \\
\text { towards System 2 }\end{array}$ & System 1 & $\begin{array}{l}\text { From System 2 } \\
\text { towards System 1 }\end{array}$ \\
\hline Example & Salience & Default & Graphic warning \\
\hline
\end{tabular}

The second degree nudges aim to use an existing bias towards a predictable outcome, an example being the default nudge, (see Table 1). There is evidence that people go along with the default option, therefore setting the 'right' default temperatures for the heating and cooling systems would be effective (BIT 2011). Sunstein refers to defaults as System 1 nudges, because they target automatic, heuristic processing (Sunstein 2016).

Another example of System 1 nudges are graphic warnings, for example on the tobacco packaging. According to Baldwin's categorization, these are third degree nudges (Table 1) because they induce a new bias (Baldwin 2014), an emotional association in this case. The implication of the three types of nudges with regard to the EPC will be further exploited in the Subsection 3.2 .

In the last decade there was a growing interest to apply libertarian paternalism to policy in many European countries such as UK, France, Denmark, Ireland, Sweden, Norway (Lunn 2013). Nudging has been applied in many areas of policy making such as consumer protection, finance, taxation and health, yet their applications in the context of energy have been limited (BIT 2015, 2016; Lourenço et al. 2016).

Nevertheless, limiting the application of behavioural economics exclusively to a hands-on list of biases is rather reductive. It is important to keep in mind the mechanisms and the assumptions behind the behavioural models (Taranu and Verbeeck 2016). For example, the balance between rational and heuristic thinking depends not only on the characteristics of the message, but also on characteristics of the individuals such as need 
for cognition (Mannetti et al. 2007), need for closure (Cacioppo et al. 1984) and need for affect (Maio and Esses 2001). These factors have to be taken into account in order to avoid an asymmetric impact in the implementation of the policy instrument (Baldwin 2014). Nudging is only one of its possible applications to policy, that preserves the freedom of choice (Sunstein 2014). Behavioural insights can also serve as basis for certain mandates, without being committed to political doctrine of choice preservation that is characteristic to libertarian paternalism (Lunn 2013; Bubb and Pildes 2014). Besides the choice of the instrument, behavioural insights might influence the way the policy instrument is implemented. The recent EU Report underline the possibility for an implicit consideration in elaborating traditional policy tools such behaviourally-informed initiatives and behaviourally-aligned initiatives (Lourenço et al. 2016). Nevertheless, while the efficacy of nudges can be tested with RCTs, the other applications are more difficult to assess, since the effect of the behavioural insight can hardly be isolated from the complex reality (Lunn 2013).

\section{Methodology}

The EPC is addressed to house owners and prospective buyers and renters, who will receive the certificate when deciding to buy or rent a property. Therefore, by reading the certificate they must be able to understand the current and potential energy performance of the dwelling without assistance from energy experts. Our research analyses how the technical information of the energy performance is translated for the dwellers and focuses on a possible rational or heuristic interpretation of the information (see section 2).

The qualitative research consists of two phases: a comparative analysis across nine European EPCs, (subsection 3.1.) and a focus group with experts (subsection 3.2.). The comparative analysis revealed a wide range of possibilities in terms of information framings and potential nudges. During the focus group, the findings of the comparative analysis were discussed under the optics of the application to the Flemish EPC. Additional insights were gained regarding the existing version of the certificate with regard of its intelligibility and impact. Another aim of the focus group was to narrow down the wide range of possible information framing derived from the comparative analysis. These framings will be further on tested with experiments on the Flemish EPC in the third phase of the research.

\subsection{Methodology of the comparative analysis}

The comparative analysis of the nine European EPCs (Germany, the Netherlands, the UK, Spain, Romania, Denmark, France and two Regions: Lombardy and Flanders) takes into 
account the possible heuristic interpretation of the information by the dwellers. Since EPCs are subject of changes, it should be noted that the versions in discussion are as of June 2015. In the choice of the certificates was taken into account their heterogeneity, both in content, length and geographical distribution.

The information framings of the certificates were analysed from the point of view of potential biases and nudges. The latter resulted from a literature review of behaviourally informed policies in energy efficiency and residential energy. Based on the three types of nudges, previously discussed in section 2.2, the following framework was elaborated and applied in the comparative analysis of the EPCs:

- First degree nudges (Baldwin 2014):

- Simple, intelligible messages (BIT 2011; Dolan et al. 2010; Lunn 2013);

Salient information (Hallsworth et al. 2014; Dolan et al. 2010)

- Second degree nudges (Baldwin 2014):

- Social norm (Hallsworth et al. 2014; Dolan et al. 2010), temporal discounting (BIT 2011) and default (Dolan et al. 2010; Frederiks et al. 2015)

- Third degree nudges:

- Anchoring (Thaler and Sunstein 2009; Lunn 2013), endowment effect (Lourenço et al. 2016)

- Relate the energy score with final destination use (heating, cooling, hot water, lighting), rendering the abstract notions of energy more tangible (Shove 2003)

The nine EPCs under study vary not only in the way they present the information, but even what information they contain and how it is calculated. Therefore, before analysing the framing of the information and the nudges (HOW, Subsection 4.2), a quick overview will be given to what key information they contain (WHAT, Subsection 4.1).

\subsection{Methodology of the focus group}

The second phase of research following the comparative analysis of the EPCs was a focus group with seven experts with technical or social background from Flanders. The focus group had the aim to analyse the findings from the comparative analysis and select the information framings and the nudges to be tested in a later stage with dwellers in a quantitative way.

The selection of participants had the purpose to complement the knowledge in energy 
performance, with knowledge in behaviour, which led to a productive discussion and even debate. Among the participants were: two EPC certifiers; an expert in energy simulations and EPC certifier; a PhD student specialised in the energy efficiency of dwellings; an energy adviser working in an NGO; two experts in behaviour working. The focus group was moderated by a researcher from the university. Five out of seven participants have direct interaction with private and social housing dwellers and shared their experience on the acceptability and impact of the Flemish certificate. The experts in behaviour gave insights on how the information might be perceived by the dwellers and whether biases and heuristics play a role in the interpretation of the information.

The discussion was not limited to the existing version of the Flemish EPC, but looked at the alternative information framings from the nine European EPCs, see section 4. Therefore, a presentation on the results of the comparative analysis accompanied the discussion. The discussion had the following structure:

- the effectiveness of the existing Flemish EPC based on the experience of the certifiers and energy experts with the dwellers;

- information framings of the energy performance indicator and of the recommendations: the array of possible information framings derived from the comparative analysis (see Table 2 and Table 3);

- possible biases in the interpretation of the existing version of the Flemish EPC and potential nudges for encouraging the uptake of the recommendations;

The main findings of the focus group are detailed in Section 5. The focus group is a qualitative method and its findings cannot be generalized. Nevertheless, it allowed to have an in depth discussion with experts with complementing expertise: in energy performance on one hand and in behavioural insights on the other hand. It resulted in a confrontation of visions and new insights. This would have not been possible with a quantitative method such as the questionnaire.

\section{Main findings of the comparative analysis}

\subsection{WHAT is present in the EPCs}

The EU Directive 2010/31/EU(EC 2002) allows freedom in the definition of the energy performance indicator. Most countries opted for an energy label that resembles the appliances label, while Flanders opted for a continuous scale (Figure 1) and Germany for both, (Table 2). The units are mainly $\mathrm{kWh} / \mathrm{m}^{2}$ per year of primary energy, while the UK indicator is the reverse: unitless energy efficiency. The main label of Spain represents the 
$\mathrm{CO}_{2}$ emissions, while other countries added a secondary indicator for the environmental impact (the UK, France, Lombardy and Flanders). Romania opted to add specific labels for heating, hot water, lighting, cooling and mechanical ventilation, besides the global label. This is a good example of making salient the final use of the energy, in order to avoid representing energy in an abstract way. Nevertheless, this could lead to the misinterpretation that the information on the EPC is personalized, while it is calculated for a standard occupancy.
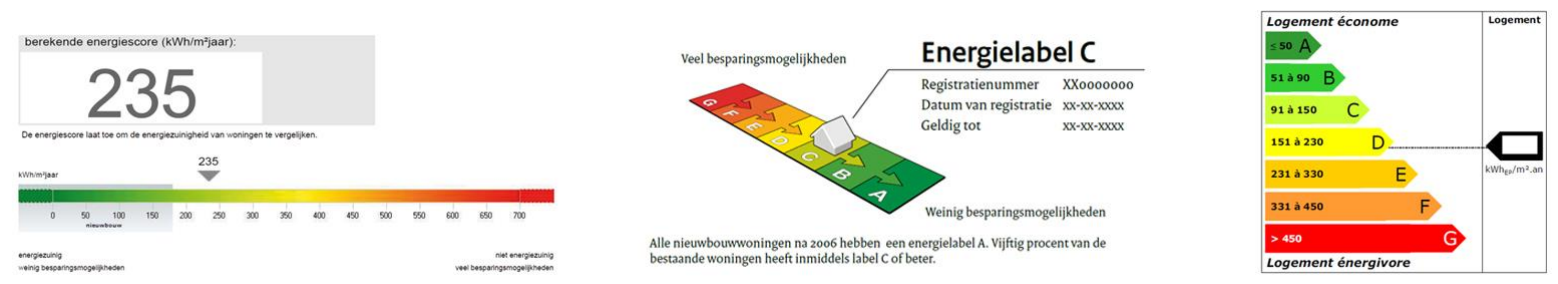

Figure 1Energy performance indicators of the EPCs. From left to right: Flanders (score and continuous scale), the Netherlands and France (labels)

Similarly, the certificates that include the photo of the dwelling (Germany, Spain, Denmark and Flanders) might benefit from the endowment effect, because often people value more what they have for the mere reason of owning it (Ariely 2008). Few EPCs contain the site plan, only the certificate of Spain and Lombardy, but it might be practical to have it when considering the placement of certain measures such as PV panels or geothermal heat pumps.

Table 2 Overview of the information present on the EPCs

\begin{tabular}{|c|c|c|c|c|c|c|c|c|c|c|}
\hline & $\mathrm{DE}$ & NL & UK & ES & RO & DK & $\mathrm{FR}$ & Lombardy & Flanders \\
\hline \multicolumn{2}{|c|}{ Number of pages } & 5 & 1 & 4 & 7 & 6 & 14 & 4 & 2 & 5 \\
\hline \multicolumn{2}{|c|}{ Online version } & - & $\checkmark$ & $\checkmark$ & - & - & $\checkmark$ & - & $\checkmark$ & - \\
\hline \multicolumn{2}{|c|}{$\begin{array}{c}\text { Photo of the } \\
\text { dwelling }\end{array}$} & $\checkmark$ & - & - & $\checkmark$ & - & $\checkmark$ & - & - & $\checkmark$ \\
\hline \multicolumn{2}{|c|}{ Site plan } & - & - & - & $\checkmark$ & - & - & - & $\checkmark$ & - \\
\hline \multirow{4}{*}{$\begin{array}{l}\text { Energy } \\
\text { rating }\end{array}$} & Label & $\checkmark$ & $\checkmark$ & $\checkmark$ & $\checkmark$ & $\checkmark$ & $\checkmark$ & $\checkmark$ & $\checkmark$ & - \\
\hline & Scale & $\checkmark$ & - & - & - & - & - & - & - & $\checkmark$ \\
\hline & $\begin{array}{l}\text { Type of } \\
\text { indicator }\end{array}$ & $\begin{array}{c}\text { primary } \\
\text { energy }\end{array}$ & - & $\mathrm{EE}$ & $\mathrm{CO}_{2}$ & $\begin{array}{c}\text { final } \\
\text { energy }\end{array}$ & - & $\begin{array}{l}\text { primary } \\
\text { energy }\end{array}$ & $\begin{array}{l}\text { primary } \\
\text { energy }\end{array}$ & $\begin{array}{l}\text { primary } \\
\text { energy }\end{array}$ \\
\hline & Units & $\begin{array}{l}\mathrm{kWh} / \mathrm{m}^{2} \\
\text { per year }\end{array}$ & - & - & $\begin{array}{c}\mathrm{kg} \\
\mathrm{CO} 2 / \mathrm{m}^{2} \\
\text { per year }\end{array}$ & $\begin{array}{l}\mathrm{kWh} / \mathrm{m}^{2} \\
\text { per year }\end{array}$ & - & $\begin{array}{l}\mathrm{kWh} / \mathrm{m}^{2} \\
\text { per year }\end{array}$ & $\begin{array}{l}\mathrm{kWh} / \mathrm{m}^{2} \\
\text { per year }\end{array}$ & $\begin{array}{l}\mathrm{kWh} / \mathrm{m}^{2} \\
\text { per year }\end{array}$ \\
\hline \multicolumn{2}{|c|}{$\mathrm{CO}_{2}$ emissions } & - & - & $\checkmark$ & $\checkmark$ & - & - & $\checkmark$ & $\checkmark$ & $\checkmark$ \\
\hline
\end{tabular}




\begin{tabular}{|c|c|c|c|c|c|c|c|c|c|}
\hline label/ scale & & & & & & & & & \\
\hline $\begin{array}{c}\text { Assessment of } \\
\text { recommendations }\end{array}$ & $\checkmark$ & - & $\checkmark$ & $\checkmark$ & - & $\checkmark$ & $\checkmark$ & $\checkmark$ & - \\
\hline
\end{tabular}

\subsection{HOW: the role of nudges}

A difficult to process information contributes to a heuristic thinking and first degree nudges aim a rational processing of this information. Yet, many of the certificates, such as the ones of Flanders and Germany, seem to be addressing experts with technical terms such as U-value, primary energy and $\mathrm{kWh} / \mathrm{m}^{2}$ per year. The certificates from the UK, France, Lombard region have 'translated' technical terms and concepts into selfexplanatory content or images. Besides, changes have been made in order to avoid overload of information and to render the key information more salient.

One of the key messages of the EPC is the energy performance of the dwelling compared to the rest of the building stock. If the first degree nudges aim to avoid existing biases, the second degree nudges use them towards a predictable outcome. "Fifty percent of existing homes are now labelled C or better" placed under the Dutch label exploits the social norm bias.

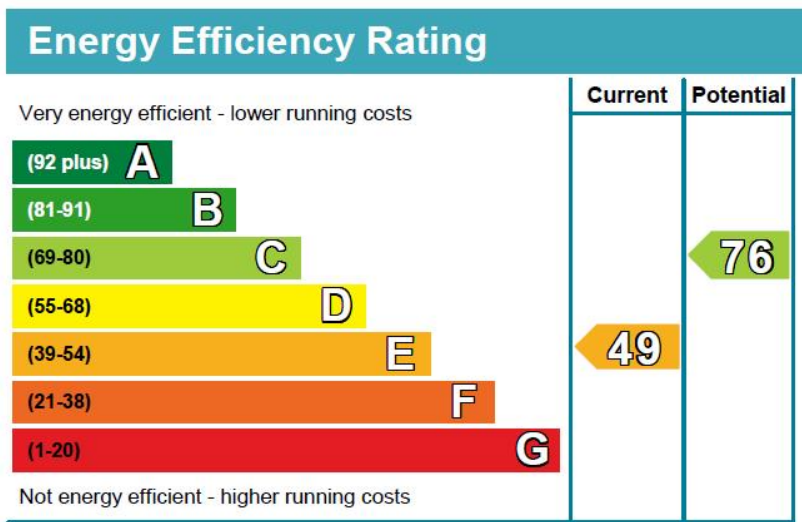

The graph shows the current energy efficiency of your home.

The higher the rating the lower your fuel bills are likely to be.

The potential rating shows the effect of undertaking the recommendations on page 3 .

The average energy efficiency rating for a dwelling in England and Wales is band D (rating $60)$.

Figure 2 Energy performance label of the EPC of the UK. Anchoring nudge - the potential energy class of the label

The third degree nudges consist in inducing a new bias. The anchoring heuristic consists in using a reference and adjusting it for an estimation (Tversky and Kahneman 1974). Yet the adjustment is often not sufficient and the final estimation depends on the initial reference, that acts as an anchor. This nudge can provide a reference for the house owner in 
evaluating the energy performance of the dwelling. In the case of Flanders, the reference provided is the grey shaded area of the scale in reference to the new construction standard ( 'nieuwbouw'), see Figure 5. Also the UK energy label contains the potential energy class achieved after undertaking the recommended measures that might work as an anchor (Figure 2).

The second important aspect of the EPC is to show the potential savings of the recommended energy efficiency measures. Flanders, the Netherlands and Romania chose not to illustrate the impact of the recommendations compared to the current energy performance of the dwelling. The rest of the EPCs contain a variety of possible ways both in content and in presentation. Most of them opted for a table (Figure 3), making the recommended measures more salient and easier to compare. The illustration of savings vary also in terms: whether by estimating energy savings (Spain), monetary savings (the $\mathrm{UK}), \mathrm{CO}_{2}$ reduction (France) or the cost per tonne of $\mathrm{CO}_{2}$ saved (Denmark), see Table 2 . These estimations have to be coherent with the units used in the label: monetary or environmental. Both have advantages and disadvantages, but it is important to use only one of the two languages, because using extrinsic (monetary) and intrinsic (environmental) motivations at once might weaken the message (Schwartz et al. 2015).

\begin{tabular}{l|c|c|c} 
Top actions you can take to save money and make your home more efficient \\
Recommended measures & Indicative cost & $\begin{array}{c}\text { Typical savings } \\
\text { over } 3 \text { years }\end{array}$ & $\begin{array}{c}\text { Available with } \\
\text { Green Deal }\end{array}$ \\
\hline 1 Increase loft insulation to $270 \mathrm{~mm}$ & $£ 100-£ 350$ & $£ 141$ & \\
\hline 2 Cavity wall insulation & $£ 500-£ 1,500$ & $£ 537$ & \\
\hline 3 Draught proofing & $£ 80-£ 120$ & $£ 78$ & \\
\hline
\end{tabular}

Figure 3 Table with energy efficiency recommendations, EPC of the UK. Nudge discounting the future

For the UK certificate (Figure 3), changes have been made, showing the savings of the recommended measures over three years instead of five years (BIT 2011). By illustrating savings over a shorter span of time, it was taken into account the hyperbolic discounting (temporal discounting or present bias).

Yet not all nudges regard information framing, an effective nudge is the automatic inscription to informational campaigns or to the online database of EPCs (the UK, the Netherlands), with the possibility to opt out (default nudge). Some countries opted for a shorter version of the paper certificate, with more extensive information available online (Denmark, the UK). 
Table 3 Overview of units for energy-efficiency recommended measures

\begin{tabular}{|c|c|c|c|c|c|c|c|c|c|c|c|}
\hline & Unit & $\begin{array}{l}\text { Assessment } \\
\text { of the } \\
\text { measure }\end{array}$ & DE & NL & UK & ES & RO & DK & FR & $\begin{array}{l}\text { Lom- } \\
\text { bardy }\end{array}$ & $\begin{array}{l}\text { Flan- } \\
\text { ders }\end{array}$ \\
\hline \multirow{7}{*}{ Monetary } & $£$ & $\begin{array}{l}\text { Investment } \\
\text { cost, savings }\end{array}$ & & & $\checkmark$ & & & & & & \\
\hline & $€ / \mathrm{kWh}$ & $\begin{array}{l}\text { Cost per kWh } \\
\text { saved }\end{array}$ & $\checkmark$ & & & & & & & & \\
\hline & $\begin{array}{c}\text { pictogram } \\
€\end{array}$ & $\begin{array}{l}\text { Investment } \\
\text { cost }\end{array}$ & & & & & & & $\checkmark$ & & \\
\hline & $\begin{array}{c}\text { pictogram } \\
\star\end{array}$ & Savings & & & & & & & $\checkmark$ & & \\
\hline & $\begin{array}{c}\mathrm{kr} . \text { and } \\
\text { tonnes } \mathrm{CO}_{2}\end{array}$ & Savings & & & & & & $\checkmark$ & & & \\
\hline & years & $\begin{array}{l}\text { Payback } \\
\text { period }\end{array}$ & $\checkmark$ & & & & & & & & \\
\hline & pictogram & $\begin{array}{l}\text { Payback } \\
\text { period }\end{array}$ & & & & & & & $\checkmark$ & & \\
\hline \multirow{4}{*}{ Energy } & $\begin{array}{l}\mathrm{kWh} / \mathrm{m}^{2} \\
\text { per year }\end{array}$ & $\begin{array}{l}\text { Reduction in } \\
\text { energy } \\
\text { demand }\end{array}$ & & & & $\checkmark$ & & & & & \\
\hline & $\%$ & $\begin{array}{l}\text { Reduction in } \\
\text { energy } \\
\text { demand }\end{array}$ & & & & & & & & $\checkmark$ & \\
\hline & $\mathrm{W} / \mathrm{m}^{2} \mathrm{~K}$ & $\begin{array}{l}\text { Performance } \\
\text { (U-value) }\end{array}$ & & & & & & & & $\checkmark$ & $\checkmark$ \\
\hline & $A+$ to $G$ & $\begin{array}{l}\text { Achieved } \\
\text { energy class }\end{array}$ & & & & & & & & $\checkmark$ & \\
\hline \multirow{3}{*}{$\begin{array}{c}\text { Envi- } \\
\text { ronmental }\end{array}$} & $\begin{array}{l}\mathrm{kg} \mathrm{CO} / 2 \mathrm{~m}^{2} \\
\text { per year }\end{array}$ & $\begin{array}{l}\text { Reduction in } \\
\mathrm{CO}_{2} \text { emissions }\end{array}$ & & & & $\checkmark$ & & & & & \\
\hline & $\%$ & $\begin{array}{l}\text { Reduction in } \\
\mathrm{CO}_{2} \text { emissions }\end{array}$ & & & & & & & & $\checkmark$ & \\
\hline & $\begin{array}{c}\text { kr. and } \\
\text { tonnes } \mathrm{CO}_{2}\end{array}$ & Savings & & & & & & $\checkmark$ & & & \\
\hline Other & $\checkmark$ & $\begin{array}{l}\text { Single } \\
\text { measure/ } \\
\text { renovation }\end{array}$ & $\checkmark$ & & & & & & & & \\
\hline
\end{tabular}




\begin{tabular}{|c|c|l|l|l|l|l|l|l|l|l|l|}
\hline & $\mathrm{m}^{2}$ & Surface & & & & & & & & $\checkmark$ & \\
\hline & $\begin{array}{c}\text { high } \\
\text { medium } \\
\text { low }\end{array}$ & $\begin{array}{l}\text { Priority of the } \\
\text { measure }\end{array}$ & & & & & & & & & $\checkmark$ \\
\hline
\end{tabular}

Legend:

Pictogram € more than 200 Euros tax incl.; €€ from 200 to1000 Euros tax incl.,€€ from 1000 to 5000 Euros tax incl.; €€€€ more than 5000 Euros tax incl.

Pictogram $\star$ more than $100 €$ tax incl./ year; $\star \star$ from 100 to $200 €$ tax incl./ year; $\star \star \star$ from 200 to $300 €$ tax incl./ year; $\star \star \star \star \star$ more than $300 €$ tax incl./ year;

Pictogram from 10 to 15 years; more than 5 years; than 15 years

Table 4 Overview of the nudges implied by the EPCs

\begin{tabular}{|l|l|c|c|c|c|c|c|c|c|c|}
\hline \multicolumn{2}{|c|}{} & DE & NL & UK & ES & RO & DK & FR & Lombardy & Flanders \\
\hline $\begin{array}{l}\text { First } \\
\text { Degree } \\
\text { Nudge }\end{array}$ & Make it easy & - & $\checkmark$ & $\checkmark$ & - & - & $\checkmark$ & $\checkmark$ & $\checkmark$ & - \\
\cline { 2 - 11 } & Make it salient & $\checkmark$ & - & $\checkmark$ & - & $\checkmark$ & $\checkmark$ & $\checkmark$ & $\checkmark$ & - \\
\hline $\begin{array}{l}\text { Second } \\
\text { Degree } \\
\text { Nudge }\end{array}$ & $\begin{array}{l}\text { Social norm } \\
\text { Temporal }\end{array}$ & $\checkmark$ & $\checkmark$ & - & - & - & $\checkmark$ & - & - & - \\
\cline { 2 - 11 } & Default & $\checkmark$ & - & $\checkmark$ & $\checkmark$ & - & - & $\checkmark$ & $\checkmark$ & - \\
\hline $\begin{array}{l}\text { Third } \\
\text { Degree } \\
\text { Nudge }\end{array}$ & Anchoring & $\checkmark$ & $\checkmark$ & $\checkmark$ & - & - & $\checkmark$ & - & $\checkmark$ & $\checkmark$ \\
\hline
\end{tabular}

\section{Main findings of the focus group}

\subsection{Thematic coding}

The discussion during the focus group with a duration of two hours was transcribed ad verbum. Simultaneously with the transcription process, notes were being taken with potential codes and comments regarding the tone of the voice, etc. Subsequently, out of all the thematic codes, the ones relevant to the research question were selected. The research questions of the focus group were: what is the impact of the existing Flemish EPC and which 
insights from the comparative analysis can be applied in order to improve it? As a basis for discussion of possible ways of presenting the information served the insights from the comparative analysis of the nine EPCs. Initially the codes were divided in three main themes: 'Impact on the dwellers' , 'Experts' perspective' and 'Biases and nudges' . In order to avoid double coding, the biases were integrated in the corresponding codes, for example, 'availability heuristic' was nested under the' score vs. label' , see Figure 4.

\subsection{Results of the focus group}

In the following section the main insights from the focus group will be detailed. The content of 'Impact on the dwellers' resulted from the reporting of practitioners such as EPC certifiers and energy advisers on their interaction with the dwellers. Only certain findings of the comparative analysis were presented to the experts: the possible framing of the information in terms of units (Table 2 and Table 3). The findings regarding the possible nudges were not presented to avoid influence on the discussion. Since some experts were not familiar with the terms of the behavioural economics, some definitions and examples of biases were given. Figure 4 lists possible biases and nudges emerged from the focus group discussion and these are different from the ones of the comparative analysis, see Table 4. 


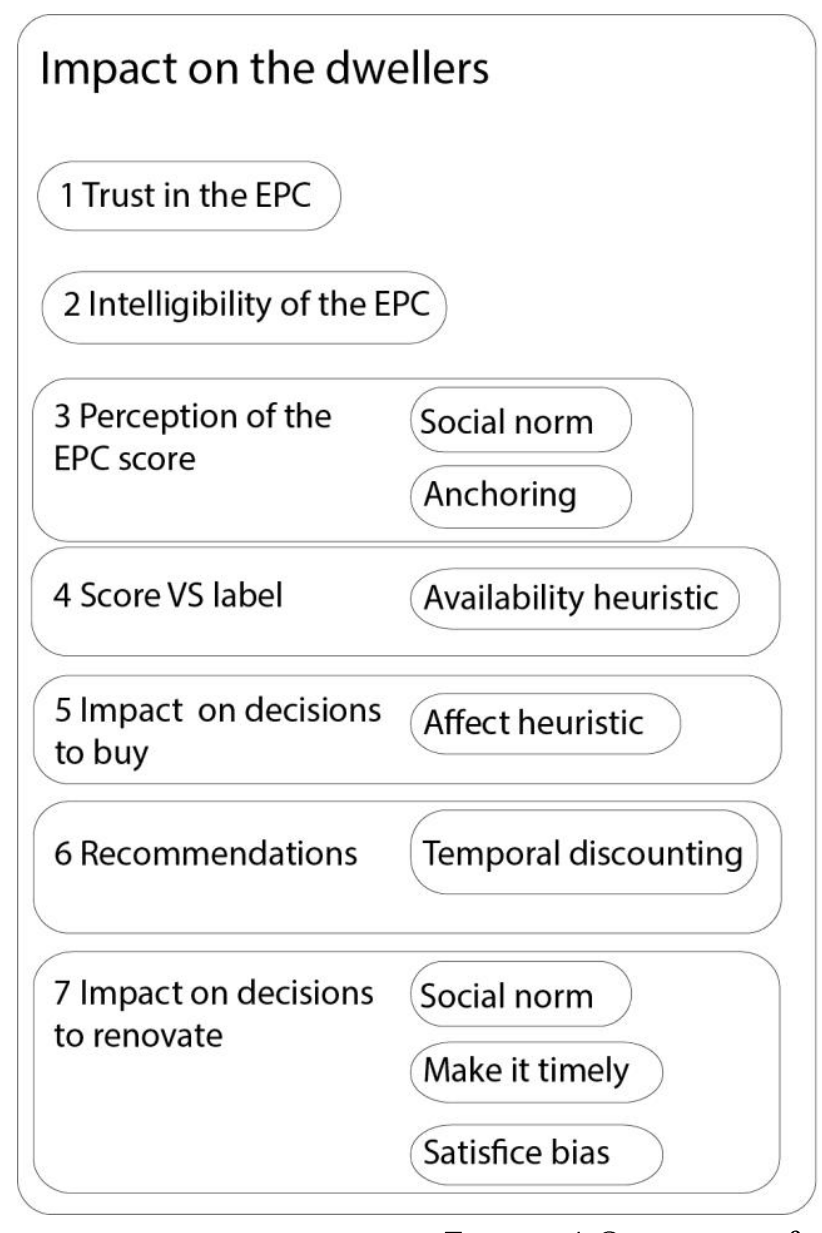

\section{Experts' perspective}

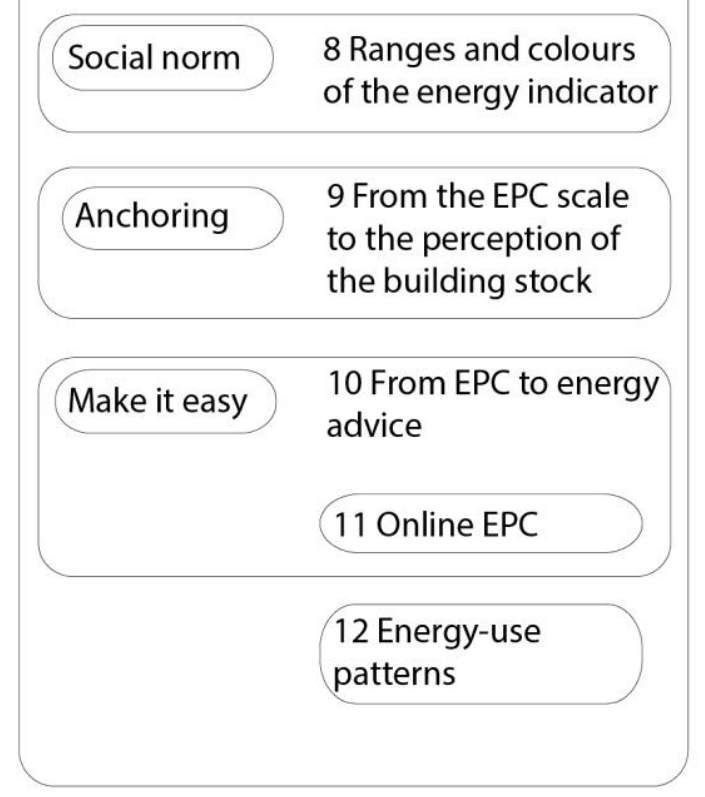

Figure 4 Overview of the themes and codes

\section{Impact on the dwellers - trust in the EPC}

Participants agreed that the existing version of the Flemish EPC is not regarded as a reliable and trustable source of information. It was recalled bad coverage in media that worsened the trust of the dwellers.

"... the house owners say: "you cannot trust the EPC number that you get, because there' s so much dependence on who is calculating it" ..." (policy maker)

Energy advisers and EPC certifiers affirmed that many dwellers do not read the certificate beyond the first page (the recommendations are listed on the third page) and some dwellers are not even aware of having it. Many experts mentioned that often house-owners perceive the certificate as a bureaucratic burden and an obligation to comply with, not as a source of information. 


\section{Impact on the dwellers - intelligibility of the EPC}

In several occasions the technical language that is beyond the level of expertise of the dwellers was mentioned. Regarding the EPC score, that is expressed in $\mathrm{kWh} / \mathrm{m}^{2}$ per year, most of the experts agreed that dwellers ignore the units and consider only the number.

$$
\begin{aligned}
& \text { “...the EPC it' s becoming something like a fashion label, } \\
& \text { “what's your EPC?, what's my EPC”, people are benchmarking the figure without } \\
& \text { knowing what it actually means” (EPC certifier) }
\end{aligned}
$$

It was underlined that the dwellers are not able to make sense of the information on the EPC on their own and they need professional assistance. The difficulty to understand the information presented might influence the lack of interest in the certificate nowadays.

3. Impact on the dwellers - perception of the EPC score. Biases and nudges - social norm and anchoring.

On the first page of the certificate, besides the address of the dwelling and of the certifying company, there is only the photo of the dwelling and the energy performance indicator. As a reference for the discussion served a certificate of a typical Flemish terraced house with the EPC score of $235 \mathrm{kWh} / \mathrm{m}^{2}$ per year (Figure 5). The energy performance score is illustrated on a coloured gradient scale from green to red and 235 is situated on the limit between green and yellow. According to the participants, the colours of the scale play an important role in assessing the energy performance of the dwelling.

"It' s like traffic lights: red is bad, green is good" (expert in behaviour, social housing)

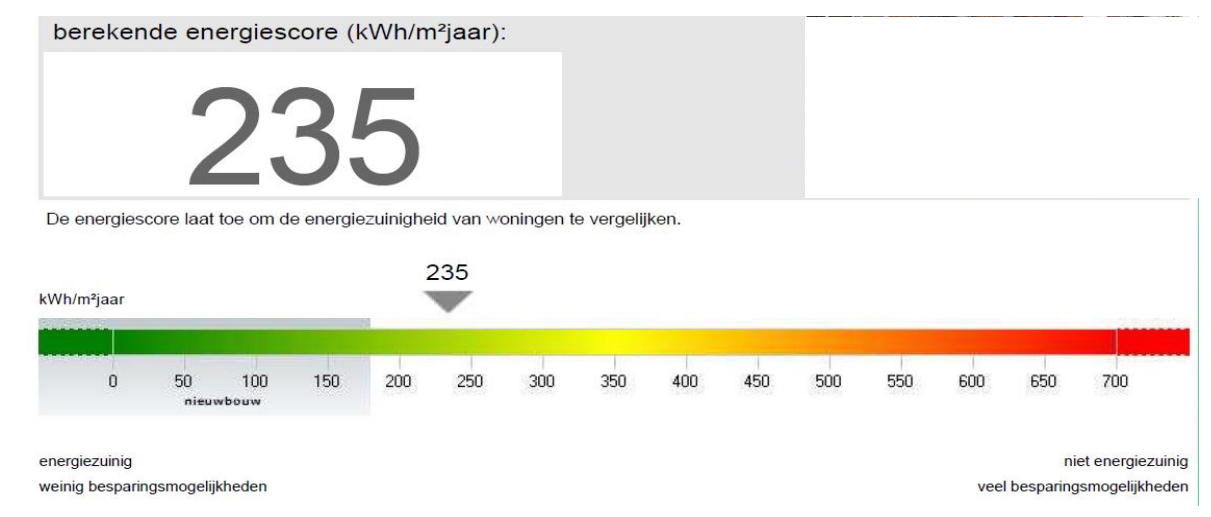

Figure 5 Energy performance indicator of the Flemish EPC: energy score and continuous scale 
Since the EPC score represents the yearly primary energy per square meter, it was pointed out by some experts that the dwellers do not perceive the effect of the size of the dwelling. The total amount of primary energy needed is shown only on the second page of the certificate, as plain text. It was argued that the dwellers should be aware of the total energy consumption in order to consider it in their decision making, therefore this number should be visible in the main energy performance indicator. On the other hand, other experts consider that having the unit $\mathrm{kWh} / \mathrm{m}^{2}$ renders the dwellings comparable in terms of energy efficiency.

\section{Impact on the dwellers - score vs. label. Biases - availability heuristic.}

All the certificates analysed contain a label as the energy performance indicator, the Flemish being the only one with a score, see Figure 1 and Table 2. The participants agreed that the label is "more familiar" and "it speaks more", because it resembles the label used for appliances. The label could be more effective because of an aspect of the availability heuristic (Kahneman et al. 1982) that is the retrievability bias - the ease with which it can be recalled since it is already present in the memory (Tversky and Kahneman 1974). Nevertheless, some experts mentioned the risk that house owners would be prone to influence the EPC certifier when the score is at the limit between two classes. Others argued that this risk, if present, could persist also with the score.

5. Impact on the dwellers - impact on decision to buy. Biases - affect heuristic.

While purchasing the house, rather than being cold-minded and take into account the energy performance stated in the EPC, people are influenced by their emotions, denoting an affect heuristic.

“...most people choose with their hearts and their feeling” expert in energy

At the same time, the certificate is "too technical", which impedes to assess the overall energy performance due to cognitive load. Instead, people pay more attention to visible aspects of the dwelling, such as "is there single glass? does it look new?" . This might contribute to a heuristic purchase decision making.

6. Impact on the dwellers - recommendations. Biases and nudges - temporal discounting.

The following is an example extrapolated from the list of recommendations (translated from Dutch): " $58.5 \mathrm{~m}^{2}$ of the roof is not insulated... An energy-efficient roof has a U-value lower than $0.4 \mathrm{~W} / \mathrm{m}^{2} \mathrm{~K}$ ". The participants have underlined that the existing recommendations are rather generic and obvious. 
"If there' s no insulation, you have to put insulation on your roof", OK, that' s nothing new." Energy adviser, NGO

Besides being standard measures, these are presented in technical terms. The properties of the new element (U-value) are stated without comparing the performance after installing it with the current situation. Figure 3 illustrates an example of such comparative table of the recommendations. Unlike the Flemish certificate, most of the European EPCs provide similar tables with the eventual energy savings, $\mathrm{CO}_{2}$ savings and other information such as investment costs, availability of funding, etc., see Table 3.

Yet, the participants of the focus group pointed out that most of the measures have a long payback time of around 30 years. The benefits over such a long time span are faded out due to temporal discounting. Therefore, showing the benefits of the renovation only in terms of monetary savings would be limitative. On the other hand, other benefits of the renovation such an improved comfort are difficult to quantify in a standardized way.

If the measures are not standard, a personalized energy advice is required, which would imply higher costs. Therefore, there is a trade-off between the quality and the price of the certificate

7. Impact on the dwellers - impact on decisions to renovate. Biases and nudges social norm, make it timely, satisfice bias.

Both the energy performance indicator and the recommendations could encourage the dwellers to look for more energy advice and eventually renovate. Nevertheless:

"Only if the number is really, really bad, people start looking at the recommendations. ...

I think when the number is green or yellow, nobody really cares about the recommendations." EPC certifier

The current wide ranges of green and yellow give the impression of "false feeling of doing slightly better" than the rest. The satisfice bias (Simon 1955) - opting for the "good enough' rather than 'the best' might 'temper thorough investments and create the lock in". Another aspect is the moment of receiving the certificate with the recommendations, when "most of your money is gone". The social norm of " $X \%$ of people buying houses with this label refurbished within the next 3 years" was suggested as a nudge. 
8. Experts' perspective: ranges and colours of the EPC indicator. Biases and nudges: social norm. 9. Experts' perspective: from the EPC scale to the perception of the existing building stock. Biases and nudges: anchoring.

The experts with a technical background stated that the EPC score presented as an example, $235 \mathrm{kWh} / \mathrm{m}^{2}$ per year, is actually too high to be in the green-yellow area of the scale, see Figure 5. Some of them proposed to assign the green colour ranges up to $100 \mathrm{kWh} / \mathrm{m}^{2}$. In this way, the example of $235 \mathrm{kWh} / \mathrm{m}^{2}$ would be in red or yellow-red spectrum, instead of the current yellow-green area. Other participants, mostly with the social sciences background, opposed rescaling, considering that it would mean shifting $90 \%$ of the existing dwellings on the market in the red area. This impression about the energy performance of the existing building stock might be emphasized by the outdated reference 'new construction' that suggests that very few existing buildings are situated in the green area. Figure 7 shows that $20 \%$ of the existing dwellings score better than $200 \mathrm{kWh} / \mathrm{m}^{2}$. Therefore the performance of the rest of the dwelling stock might be underestimated, contributing to an optimistic evaluation of the EPC score of ones dwelling.

10. Experts' perspective - from EPC to energy advice. Nudge - make it easy. 11. Online EPC. 12. Energy-use patterns.

A recurrent topic during the discussion was the standard occupancy input of the calculations, which does not reflect the actual energy-use patterns of the dwellers. This translates into generic recommendations that do not show the full potential of the energy efficiency measures. An online tool was suggested, that would incorporate the energy usage patterns. The tool would also facilitate energy simulations for architects and other energy advisors. An important aspect is the link from the certificate to the online tool, via a QR code, in order to remove the barriers and frictions for an action, known as 'make it easy' nudge.

\section{DISCUSSION}

The focus group discussions have pointed out repeatedly the need to integrate the user patterns into the EPC, whether it is online or on paper. It would imply an energy screening and advice that goes beyond the existing default values and standard recommendations. As other reports point out, there is a trade-off between the quality and the cost of the certificate (Sutherland et al. 2015). Thus there is the need for a better definition of the purpose of the Flemish EPC. Is it only a first insight on the energy performance as in the Netherlands or a detailed energy advice as in Denmark? For now, many EPCs, including the Flemish, are half way between the two models and delude the expectations of both dwellers and policy makers. 
The paper version of the Flemish EPC presents a limited number of generic recommendations that could be complemented with an online tool. A new voluntary policy tool is under development, the building passport (Fabbri et al. 2016). Besides the inclusion of user patterns, a long term roadmap for the energy renovation of the dwelling will be provided. Since the EPC is compulsory, it should work as a 'bridge' towards the building passport. During the focus group, is was suggested that the online tool could be accessed via a QR or bar code directly from the paper version of the EPC. This nudge, 'make it easy' , reduces the frictional, extra hassle of undertaking an action (Hallsworth et al. 2014).

The dwellers might be likely to undertake further personalized energy advice if the certificate will show the energy performance and its potential in a clear and convincing way. Since the focus group provided clues that the EPC score and the coloured scale has the biggest impact, its rescale has to be considered. According to the Flemish EPC, a dwelling with the energy score of $235 \mathrm{kWh} / \mathrm{m}^{2}$ per year of primary energy is on the green-yellow part of the scale, while on the German EPC it is on red part of the scale (Figure 6).
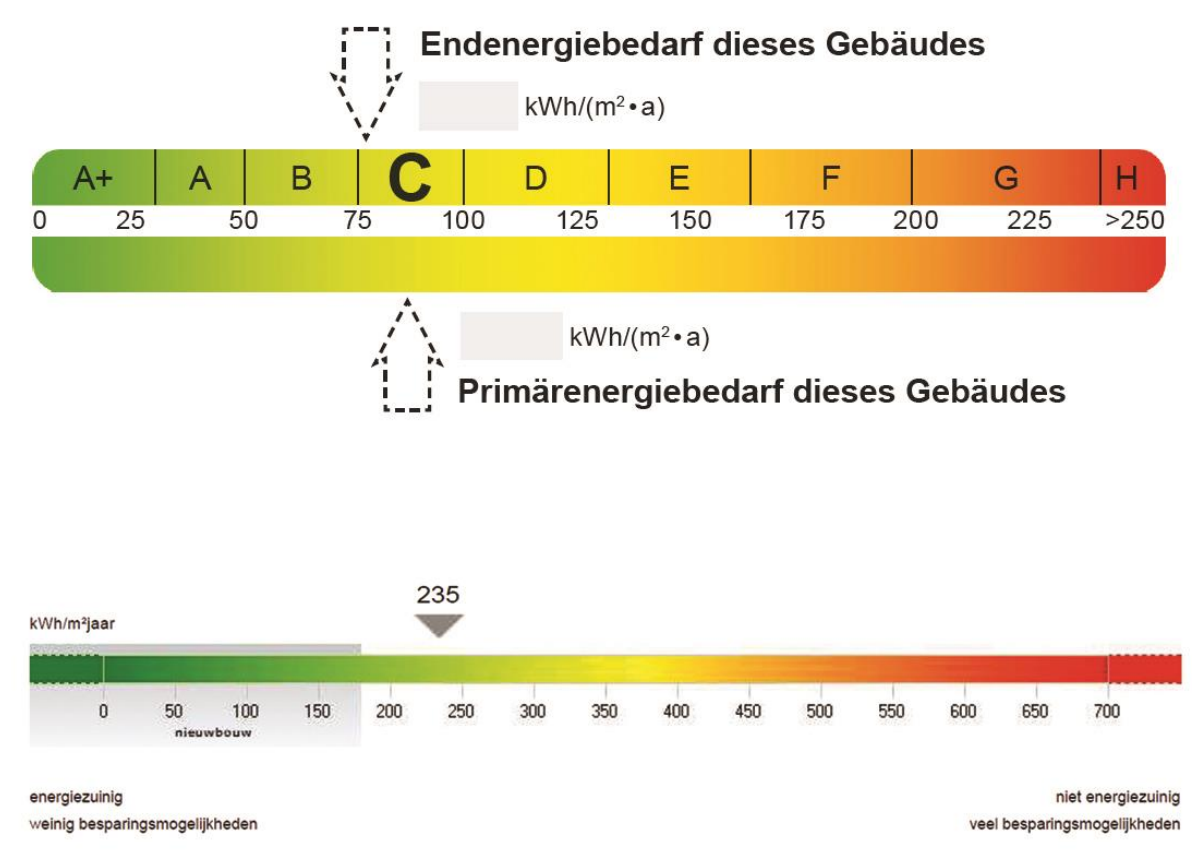

Figure 6 The scales of the energy performance certificates. Upper - EPC of Germany, lower EPC of Flanders

At the European level, due to differences in climatic conditions and building typologies, common guidelines regarding the ranges of scale cannot be provided in absolute terms, such as $\mathrm{kWh} / \mathrm{m}^{2}$ per year. These ranges of the colour gradients must be adjusted for each 
member state according to:

- the energy performance of the existing building stock

- the minimum requirements for the new construction

- the policy targets

In the case of Flanders, if the continuous scale of the EPC is overlapped with graph of the distribution of the dwellings according to the EPC score (Verbeeck and Ceulemans 2015), Figure 7 , the following can be derived:

- The green area (less than $100 \mathrm{kWh} / \mathrm{m}^{2}$ per year) includes $1 \%$ of the dwellings

- The green-yellow (from 100 to $300 \mathrm{kWh} / \mathrm{m}^{2}$ per year) - 40\% of the dwellings

- The yellow area (from 300 to $400 \mathrm{kWh} / \mathrm{m}^{2}$ per year) - 16\% of the dwellings

- The yellow-red area (from 400 to $600 \mathrm{kWh} / \mathrm{m}^{2}$ per year) $-25 \%$ of the dwellings

- The red area (more than $600 \mathrm{kWh} / \mathrm{m}^{2}$ per year) - $18 \%$ of the dwellings

The above data represent the existing dwellings from Flanders that received an EPC certification by 2012. The data does not include the new constructions that require EPB certificates, therefore the existing dwellings on the market perform even better. $57 \%$ of the existing dwellings have energy scores situated in the green, yellow-green and yellow areas of the scale. The experts agreed that if a house owner receives a certificate with green or yellow scores, most likely he will not look for further energy advice.

During the focus group there was a debate between experts with technical background, who urged to rescale the colour gradients. On the other hand, participants lacking knowledge in energy performance, were against rescaling. Possibly due to an illusion of a normal distribution of the existing dwellings according to the energy performance score if overlapped on the EPC scale, while in fact it is left skewed, see Figure 7 . They argued that a rescaling of the colour gradients would imply that the majority of the existing dwelling would be in the red area of the scale, losing the sensitivity of comparison. This illusion of a normal distribution might be caused also by the outdated value of the 'new construction' of $180 \mathrm{kWh} / \mathrm{m}^{2}$. The minimum value required for the new construction in 2016 is E50 (around $80 \mathrm{kWh} / \mathrm{m}^{2}$ ) and it is gradually getting lower. As the focus group discussion revealed, it might give the house owner the false impression of having a better energy performance of his dwelling by underestimating the performance of the rest of the building stock. This bias has to be further validated with experiments with dwellers. If confirmed, a rescaling of the EPC scale or its colour gradients would be necessary. 


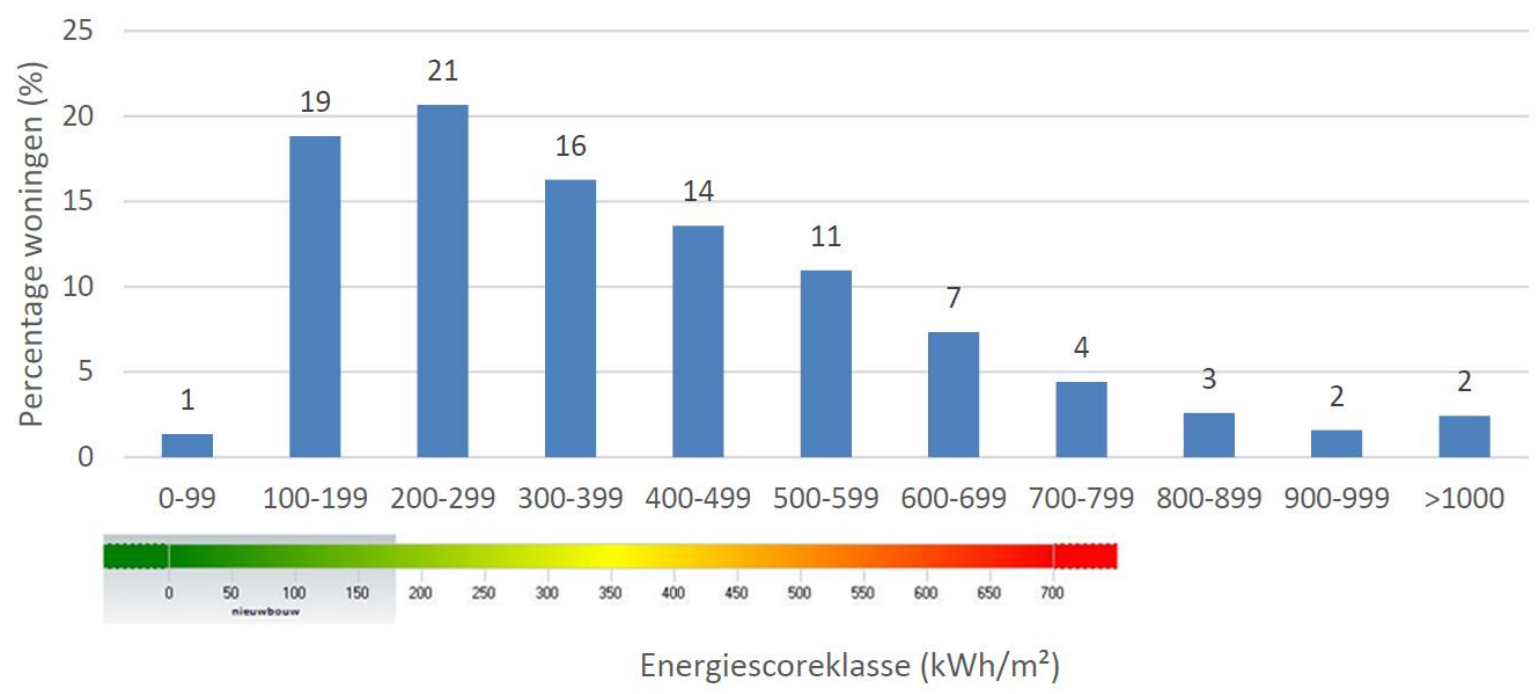

Figure 7 Distribution of the dwellings according to the EPC score (Verbeeck and Ceulemans 2015) and the scale of the energy performance indicator of the Flemish EPC. Data from 2012

An alternative to the rescaling would be a social norm nudge. In the case of a normal distribution, the mean and the median are the same, while in a left skewed graph the median is lower because of the outliers. Representing the median instead of the mean is advisable - "50\% of the dwellings score less than X" , where X is the median. It is important to verify experimentally whether the nudges are effective enough and compare it to the effect of rescaling the ranges or the colours of the scale.

The previous analysis concerns comparing the EPC score in relative terms to the rest of the Flemish building stock. Yet, the dwelling can be compared in absolute terms to an energy efficient dwelling and the scale should reflect the long term policy goals. By 2050 Germany aims for 'best possible principle per dwelling' and an average of 34-40 kWh/m $\mathrm{m}^{2}$ per year for the existing building stock (Fabbri et al. 2016). The ranges of the scale of the German EPC are in line with this target. Flanders aims for a maximum of $100 \mathrm{kWh} / \mathrm{m}^{2}$ per year for all the existing dwellings, therefore there is the need to rescale the ranges of the energy performance indicator. Besides, the 'new construction' reference has to be updated to the present minimum requirements.

\section{CONCLUSIONS}

Even though the EPC is regarded as a key policy instrument in promoting energy efficiency in the residential sector, so far its impact on the purchase and rental decisions is quite limited (Mudgal et al. 2013) (Christensen et al. 2014). The undertaken qualitative analysis 
points out that information framing is an important aspect in the implementation of the EPC, alongside quality control in the calculation software and training of the energy experts. The bounded rationality and the heuristic thinking have to be taken into account in the elaboration of the certificate. Even though the existence of the biases listed in Figure 4 and Table 4 is supported by studies in other field of policy making, its application to the energy context is yet to be investigated. The next stage of our research will be to test the insights from the comparative analysis and the focus group with experiments with dwellers. The comparative analysis revealed a wide range of possible information framings, for illustrating the key messages and the technical concepts of the certificate. Each member state has to define a priori what is the purpose of the EPC. There are two possible purposes, that will influence the length, the content and the layout of the certificate. Is it a first insight into the current situation of the dwelling and its potential, with generic recommendations or is it a detailed and tailored energy advice? Certain EPCs, including the Flemish, are at half way between the two models and contain a lot of technical specifications, even though the recommendations provided are rather standard and generic. It is important to notice that there is the trade-off between the cost and the quality of the recommendations.

At the same time, Germany, France and the Region of Flanders are developing a new policy instrument, the building renovation passport (Fabbri et al. 2016). It aims to provide a roadmap of a renovation process in phases, with personalised and detailed energy advice. If the existing EPC scheme is compulsory, the building passport will be a voluntary scheme (Fabbri et al. 2016). If the purpose of the EPC is to be a 'bridge' towards the building passport, encouraging the house owner to seek for further energy advice, it is important that it gives a clear first assessment of the current and potential energy performance of the dwelling. This underlines even more the necessity to test whether the information presented to the dwellers is perceived as it is intended, without biases.

The comparative analysis and the focus group indicate that the existing energy performance indicator of the Flemish certificate might contribute to an unjustified optimistic appreciation of the energy performance of the dwelling. The factors contributing are: the range of the scale up to $700 \mathrm{kWh} / \mathrm{m}^{2}$, the wide spectrum of the green and yellow colours and the outdated reference value of the 'new construction'. It is important to verify experimentally whether the energy performance indicator gives an accurate understanding of the energy performance of the dwelling in comparison with the rest of the building stock. At the European level, common guidelines regarding the ranges energy performance indicator can be provided relative to specifics of the members state: the energy performance of existing building stock, the minimum requirements for the new construction and the 
policy targets for 2050.

Another important aspect is the choice of the units for the energy performance indicator, as well as for the recommendations. The comparative analysis revealed a wide range of units, denoting energy consumption, energy efficiency, $\mathrm{CO}_{2}$ emissions, monetary savings or even unitless. Whether these are monetary or environmental can contribute to extrinsic or intrinsic motivations to undertake the recommended energy efficiency measures.

The existing heterogeneity of the European EPCs provides us with a rich variety of possibilities whose efficacy can be compared and tested. This qualitative analysis gives an overview of various approaches at European level, as well as more concrete biases and nudges to be tested experimentally for the Flemish EPC. No message is neutral and even if nudging is not a purpose, the heuristic thinking might influence the understanding of the energy performance and of the potential of the dwelling. These are the first steps and further research is needed in order to provide guidelines at the EU level in order to render the EPC an effective communication tool with the dwellers.

\section{REFERENCES}

Arcipowska, A., Anagnostopoulos, F., Mariottini, F., \& Kunkel, S. (2014). Energy Performance Certificates Across the EU. A mapping of national approaches. (pp. 60): BPIE.

Ariely, D. (2008). Predictably irrational: the hidden forces that shape our decisions. New York, NY: Harper.

Backhaus, J., Tigchelaar, C., \& de Best-Waldhober, M. (2011). Key findings \& policy recommendations to improve effectiveness of Energy Performance Certificates \& the Energy Performance of Buildings Directive (pp. 47): IDEAL EPBD Improving Dwellings by Enhancing Actions on Labelling for the EPBD.

Baldwin, R. (2014). From Regulation to Behaviour Change: Giving Nudge the Third Degree. Modern Law Review, 77(6), 831-857, doi:10.1111/1468-2230.12094.

BIT (2011). Behaviour Change and Energy Use. (pp. 35): Behavioural Insights Team.

BIT (2015). Update report 2013-2015. (pp. 60): The Behavioural Insights Team.

BIT (2016). Update Report 2015-16. (pp. 100): The Behavioural Insights Team.

BPIE (2010). Energy Performance Certificates across Europe. From design to implementation. (pp. 71): Buildings Performance Institute Europe BPIE.

Bubb, R., \& Pildes, R. H. (2014). How behavioural economics trims its sails and why. Harvard Law Review, 127(1593), 1594-1678.

Cacioppo, J. T., Petty, R. E., \& Kao, C. F. (1984). The Efficient Assessment of Need for Cognition. Journal of Personality Assessment, 48(3), 306-307, doi:DOI 10.1207/s15327752jpa4803_13.

Christensen, T. H., Gram-Hanssen, K., de Best-Waldhober, M., \& Adjei, A. (2014). Energy retrofits of Danish homes: is the Energy Performance Certificate useful? Building 
Research \& Information, 42(4), 489-500.

Dolan, P., Hallsworth, M., Halpern, D., King, D., \& Vlaev , I. (2010). MINDSPACE Influencing behaviour through public policy. (pp. 96): Institute for Government.

EC (2002). Directive 2002/91/EC. In The European Parliament and the Council (Ed.), On the energy performance of the buildings Official Journal of the European Communities.

EC (2010). Directive 2010/31/EU In The European Parliament and the Council of the European Union (Ed.), On the energy performance of buildings (recast). Official Journal of the European Union.

Fabbri, M., Groote, M. D., \& Rapf, O. (2016). Building renovation passports. Customised roadmaps towards deep renovation and better homes. BPIE.

Finucane, M. L., Alhakami, A., Slovic, P., \& Johnson, S. M. (2000). The affect heuristic in judgments of risks and benefits. Journal of Behavioral Decision Making, 13(1), 1-17.

Frederick, S., Loewenstein, G., \& O'Donoghue, T. (2002). Time Discounting and Time Preference: A Critical Review. Journal of Economic Literature, 40(2), 351-401, doi:10.1257/002205102320161311.

Frederiks, E. R., Stennerl, K., \& Hobman, E. V. (2015). Household energy use: Applying behavioural economics to understand consumer decision-making and behaviour. Renewable \& Sustainable Energy Reviews, 41, 1385-1394, doi:10.1016/j.rser.2014.09.026.

Hallsworth, M., Service, O., Halpern, D., Algate, F., Gallagher, R., Nguyen, S., et al. (2014). EAST Four simple ways to apply behavioural insights.

Harsman, B., Daghbashyan, Z., \& Chaudhary, P. (2016). On the quality and impact of residential energy performance certificates. Energy and Buildings, 133, 711-723.

IDEAL EPBD Project Improving Dwellings by Enhancing Actions on Labelling for the EPBD. https://ec.europa.eu/energy/intelligent/projects/en/projects/ideal-epbdMay 2016.

Kahneman, D., Slovic, P., \& Tversky, A. (1982). Judgment under uncertainty: Heuristics and biases: Cambridge University Press.

Kahneman, D., \& Tversky, A. (1979). Prospect Theory: An Analysis of Decision under Risk. Econometrica, 47(2), 263-291, doi:10.2307/1914185.

Lourenço, J. S., Ciriolo, E., Almeida, S. R., \& Troussard, X. (2016). Behavioural Insights Applied to Policy. European Report 2016. (pp. 54): European Comission. Joint Research Centre JRC.

Lunn, P. (2013). Behavioural Economics and Regulatory Policy. Public Governance and Territorial Development Directorate.

Maio, G. R., \& Esses, V. M. (2001). The need for affect: Individual differences in the motivation to approach or avoid emotions. Journal of Personality, 69(4), 583-615, doi:Doi 10.1111/1467-6494.694156.

Maivel, M., Kuusk, K., Simson, R., \& Kurn, J. (2016). Overview of existing surveys on energy performance related quality and compliance. (pp. 104): QUALICHeCK Project.

Mannetti, L., Pierro, A., \& Kruglanski, A. (2007). Who regrets more after choosing a nonstatus-quo option? Post decisional regret under need for cognitive closure. Journal of Economic Psychology, 28(2), 186-196, doi:10.1016/j.joep.2005.12.004.

Mudgal, S., Lyons, L., Cohen, F., Lyons, R., \& Fedrigo-Fazio, D. (2013). Energy 
performance certificates in buildings and their impact on transaction prices and rents in selected EU countries. (pp. 158): Final report prepared for European Commission (DG Energy).

Perez-Lombard, L., Ortiz, J., González, R., \& Maestre, I. (2008). A review of benchmarking, rating and labelling concepts within the framework. Energy and Buildings, 41, 272278.

Rabin, M. (1998). Psychology and Economics. Journal of Economic Literature, 36(1), 11-46.

RenoValue RenoValue project: a training toolkit to integrate energy efficiency and renewable energy into property valuation practices. http://renovalue.eu/. Accessed May 2016.

Schwartz, D., Bruine de Bruin, W., Fischhoff, B., \& Lave, L. (2015). Advertising Energy Saving Programs: The Potential Environmental Cost of Emphasizing Monetary Savings. Journal of Experimental Psychology: Applied, 21(2).

Shove, E. (2003). Converging Conventions of Comfort, Cleanliness and Convenience. Journal of Consumer Policy, 26(4), 395-418.

Simon, H. A. (1955). A Behavioral Model of Rational Choice. The Quarterly journal of economics, 69(1), 99-118.

Simon, H. A. (2000). Bounded rationality in social science: Today and tomorrow. Mind \& Society, 1(1), 25-39, doi:10.1007/bf02512227.

Sunstein, C. R. (2014). Nudges VS Shoves. Five reasons for choice-preserving approaches. Harvard Law Review Forum, 210-217.

Sunstein, C. R. (2016). People Prefer System 2 Nudges (Kind Of). Duke Law Journal, 66, doi:http://dx.doi.org/10.2139/ssrn.2731868.

Sutherland, G., Audi, P. G., \& Lacourt, A. (2015). 2016 Implementing the Energy Performance of Buildings Directive (EPBD). CA EPBD III.

Taranu, V., \& Verbeeck, G. (2016). Overview of dual process behavioural models and their implications on decision-making of private dwellers regarding deep energy renovation. In M. Prins, H. Wamelink, B. Giddings, K. Ku, \& M. Feenstra (Eds.), WBC 2016 CIB World Building Congress, Tampere, 2016 (Vol. II, pp. 591-603, Environmental Opportunities and challenges. Constructing commitment and acknowledging human experiences.)

Thaler, R., \& Sunstein, C. R. (2009). Nudge : improving decisions about health, wealth, and happiness. London Penguin books.

Tversky, A., \& Kahneman, D. (1974). Judgment under Uncertainty: Heuristics and Biases. Science, 185(4157), 1124-1131.

Verbeeck, G., \& Ceulemans, W. (2015). Analyse van de EPC databank. Resultaten tot en met 2012. (pp. 82). Leuven: Steunpunt Wonen.

Wade, J., \& Eyre, N. (2015). Energy Efficiency Evaluation: The evidence for real energy savings from energy efficiency programmes in the household sector. (pp. 68): UKERC UK Energy research Centre.

Wahlstrom, M. H. (2016). Doing good but not that well? A dilemma for energy conserving homeowners. ENERGY ECONOMICS, 60, 197-205.

Zajonc, R. B. (1980). Feeling and thinking: Preferences need no inferences. American Psychologist, 35(2), 151--175. 